\title{
Performance Evaluation of Multilevel AC/DC Converter for Power Quality Improvement with DC Bus Capacitor Voltage Balancing
}

\author{
Humeera Altaf, Dr.Leena G, Dr.Abdul Hamid Bhat \\ Dept. of EEE FET,Manav Rachna International University, Faridabad, India \\ Dept. of EEE FET,Manav Rachna International University, Faridabad, India \\ Dept. of EE National Institute of Technology, Srinagar, Jammu and Kashmir, India
}

\begin{abstract}
Multilevel converters, a new breed of power converters have been under research and development for more than three decades and have found successful in various medium and high power industrial applications. However, this is still a technology under development, and many new contributions and new commercial topologies have been reported in the last few years. The general structure of the multilevel converter is to synthesize a sinusoidal voltage from several levels of $d c$ voltage. This paper presents the design of neutral-point-clamped multilevel converter employing sinusoidal pulse width modulation control technique which is simulated using MATLAB/Simulink. The main objective of this paper is to improve power quality of the supply by reducing THD. The operating principles, voltage balancing methods, and limitations of the converter are analyzed together with extensive simulation results.
\end{abstract}

Keywords: Power quality; improved power quality converters; multilevel converters; harmonics compensation; voltage unbalancing

\section{Introduction}

In recent years, many power electronic converters utilizing switching devices are being widely used in domestic, commercial and industrial applications, ranging from few watts to MWs. However these converters suffer from the drawbacks of harmonic generation and reactive power flow from the source and offer highly non-linear characteristics $[1,2]$. Some of the commonly used AC/DC converters have been simulated using MATLAB/ Simulink software in this paper. The waveforms of source voltage and source current in all the cases is shown through simulation and the harmonic spectrum of source current in all the cases has been obtained to prove the power quality problems (like injection of harmonics in source current and deterioration of input power factor) created by these converters. Classically, shunt passive filters consisting of tuned LC filters and/or high pass filters are used to suppress the harmonics. The shunt passive filters are tuned most of the time to a particular harmonic frequency to be eliminated [3].However these filters suffer from various drawbacks as for good level of compensation one needs as many filters as the number of harmonics to be eliminated, also increase in harmonic current component can overload the filter.

Extensive research is being carried out in the field of harmonics to overcome these limitations. Recently the equipment used for the harmonic compensation is known as Active Power Filters (APFs) [4]. These filters have provided the required harmonic filtering and control performance in comparison to the conventional shunt passive filters and static var compensators. In addition to the current harmonics APFs are also used to eliminate voltage harmonics, for load balancing, to regulate the terminal voltage, to suppress the voltage flickers, etc. However, the APFs suffer from the drawback of large size and rating (in some cases, the filter rating may be comparable with that of the load), complexity in the control and cost $[5,6,7]$.

However a new breed of AC/DC Power Converters has been developed to overcome all the drawbacks of passive filters, var compensators and active power filters used for harmonics elimination and hence eliminates their use in the system. This new breed of converters is known as Improved power quality converters specifically known as Power Factor Correction Converters (PFCs), Switched Mode Rectifiers (SMRs), PWM Converters, Improved Power Quality Converters (IPQCs), and High Power Factor Converters (HPFCs) [8]. They are included as an inherent part of the AC-DC conversion system which produces excellent power quality at the line-side and load-side, higher efficiency, and reduced size. The power quality issues created by the use of conventional AC/DC converters are elegantly addressed by IPQCs. IPQCs have generated tremendous interest among the researchers and application engineers to solve the increasing power quality problems [9].

Broadly, Three-phase Improved Power Quality Converters have been classified on the basis of the converter topology as Boost, Buck, Buck-Boost and Multilevel converters with unidirectional and bi-directional power flow and the type of converter used as unidirectional and bi-directional converters. B. Singh, et. al. [9] presented the broad classification of three-phase IPQCs. In case of three-phase boost converters, the output 
voltage is greater than the peak input voltage [29]. Three-phase, buck converters produce output voltages less than the converter input voltage. However, the three-phase buck-boost type AC/DC converters have step-up or step-down output voltage characteristics and also the capability of limiting the in rush and DC short-circuit currents but these three-phase bidirectional buck-boost converters can be used for medium power applications whereas multilevel converter are used for higher voltage and higher power applications [9].The paper presents the work based on multilevel IPQC converter.

\section{Multilevel Converters}

Multilevel Converters (MLCs) are gaining widespread popularity because of their excellent performance with reduced THD of input current, high supply power factor, ripple-free regulated DC output voltage, reduced voltage stress of devices, reduced dv/dt stresses, and hence lower EMI emissions [10]. They also avoid the use of transformers in some applications which further enhances the efficiency of these converters. Moreover, in case of a multilevel converter, each device is stressed to a voltage $\mathrm{Vdc} /(\mathrm{n}-1)$, where $\mathrm{Vdc}$ is the DC-bus voltage and $\mathrm{n}$ is the number of levels. Hence the device stress is considerably reduced as the number of levels increases [16].This makes multilevel converters the best choice for the high-voltage and highpower applications and they have invited a lot of attention for high-power industrial applications [19].

J. S. Lai and F. Z. Peng [10] classified the bidirectional MLCs into three main categories as diodeclamped MLC, flying capacitor MLC, and cascaded MLC. In case of diode-clamped multilevel converters, the reactive power flow control is easier. But the main drawback of this converter is that excessive clamping diodes are required when the number of levels is high. In case of flying capacitor multilevel converters, large amount of storage capacitors provides extra ride through capabilities during power outage. But main drawback is that a large number of capacitors is required when the number of levels is high which makes the system less reliable and thus more difficult to package. In case of cascaded multilevel converters, least number of components is required and modularized circuit layout and packaging is possible because each level has the same structure and there are no extra clamping diodes or voltage balancing capacitors. But the main drawback is that it needs separate DC sources, thus making its applications somewhat limited. The topology used in this paper is neutral point diode clamped multilevel converter as this type of topology is advantageous for lower levels. Diode-clamped multilevel converter is the most popularly used topology among the multilevel power converters $[11,15,23]$.

Various modulation strategies have been researched for the control of multilevel bidirectional converters. The performance of a three-phase, three-level neutral point clamped converter using sinusoidal pulse width modulation (SPWM) technique is evaluated in this paper. Fig1 shows the power circuit of a three-phase three-level (neutral-point clamped) converter. The independent power switches $\left(T_{x 1}\right.$ and $\left.T_{x 2}, x=a, b, c\right)$ are controlled in each leg of the converter. The constraints for four power switches in an arm of the converter are defined so as to avoid the power switches conducting at the same time.

$$
T_{x i}+T_{x i}^{\prime}=1
$$

where $T_{x i}=1$ (or 0 ) the power switch $T_{x i}$ is turned on (or off) and $\mathrm{x}=\mathrm{a}, \mathrm{b}, \mathrm{c}$ and $i=1,2$.

Four switching states are possible for each converter leg. However, only three valid switching states can be generated to achieve three voltage levels on the AC terminals of converter leg [2].

\begin{tabular}{|c|c|c|c|c|c|}
\hline$s$ & $T_{x 1}$ & $T_{x 2}$ & $T_{x 1^{\prime}}$ & $T_{x 2^{\prime}}$ & $V_{x n}$ \\
\hline 1 & 1 & 1 & 0 & 0 & $V_{1=} V_{0} / 2$ \\
\hline 0 & 0 & 1 & 1 & 0 & 0 \\
\hline-1 & 0 & 0 & 1 & 1 & $V_{2}=-V_{0} / 2$ \\
\hline$x=a, b, c$.
\end{tabular}

Table.1. Valid switching states of the power switches of three legs and the corresponding voltages on the ac side of the converter. 


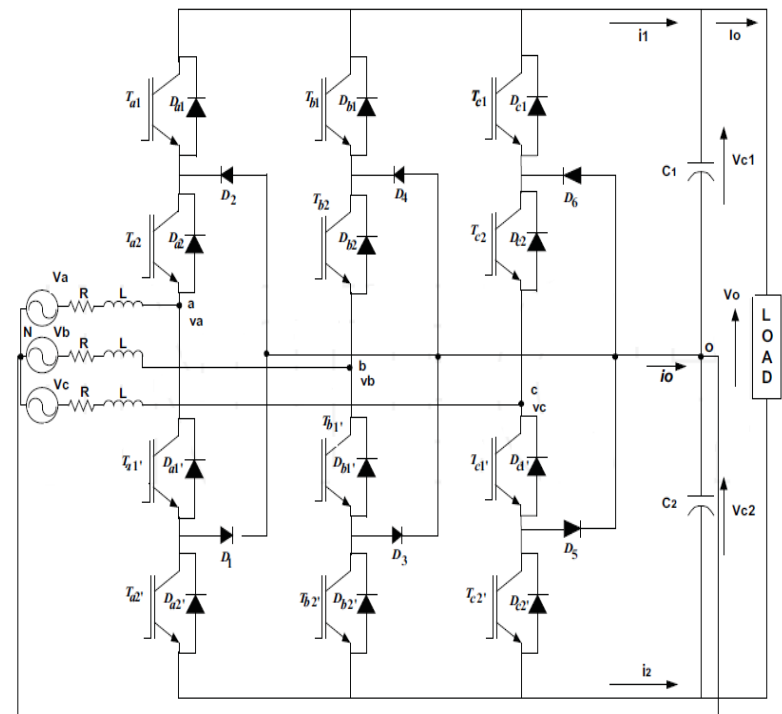

Fig.1 Three-Phase Neutral-Point Clamped three level Converter.

In three phase neutral point clamped converter, the neutral point of DC bus is connected to the neutral of three-phase AC source as shown in Fig. 1 [15]. If the two capacitor voltages $\mathrm{V}_{l}$ and $\mathrm{V}_{2}$ are equal, i.e., $\Delta V=0$, then there are three voltage levels, $V o / 2,0$ and - Vo/2, on the AC side (line-to-neutral voltages) of the converter. By proper combinations of the power switches of any arm, three different voltage levels are generated in the line-to-neutral voltage by the converter. In the same manner, during the negative half cycle of mains voltage of phase $\mathrm{A}$, two voltage levels 0 and $-V o / 2$, are produced in $\mathrm{V}_{\mathrm{ao}}$.

\section{Simulation Results}

In this paper Power quality NPC converter model is proposed, shown in Fig.2, in which PI controller is employed and SPWM technique is used. Three unipolar PWM waveforms are generated on the three phases on input side of the converter based on carrier-based PWM scheme, resulting in sinusoidal source current waveform.

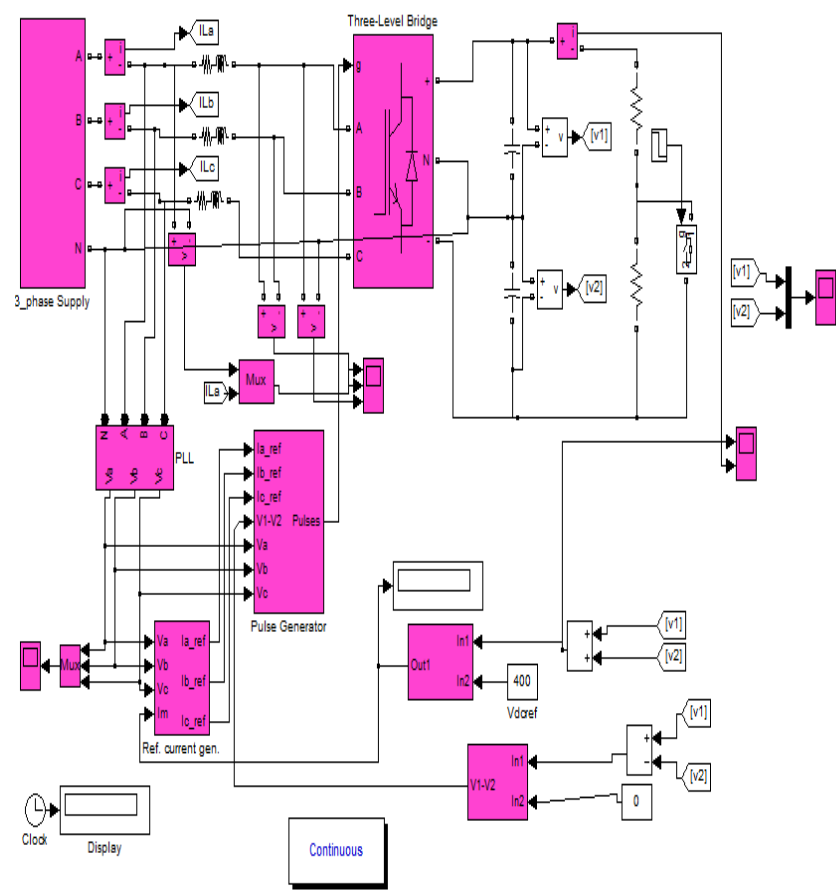

Fig 2.Simulation model of three phase improved power quality three level NPC converter 
The various performance indices are obtained after simulations using MATLAB/Simulink software and shown in Fig. 3-11.The performance of fully controlled converters without control strategy is shown in Fig 3 and 4 .

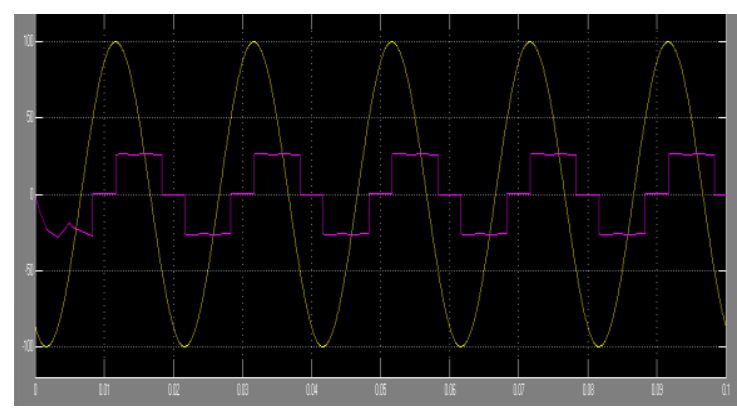

Fig 3. Source voltage (yellow) and Source current of three phase fully controlled converter (purple).

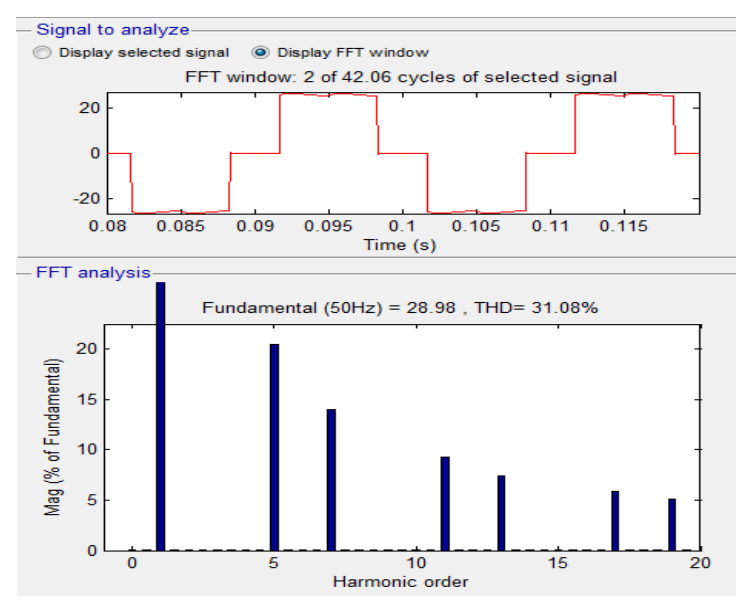

Fig 4. Harmonic spectrum of source current of three phase fully controlled converter.

From the figs 3 and 4 it is to be noted that the phase controlled converters create serious power quality problems in terms of distortion of source current causing much higher THD values. However, according to IEEE standards THD must be below $5 \%$.

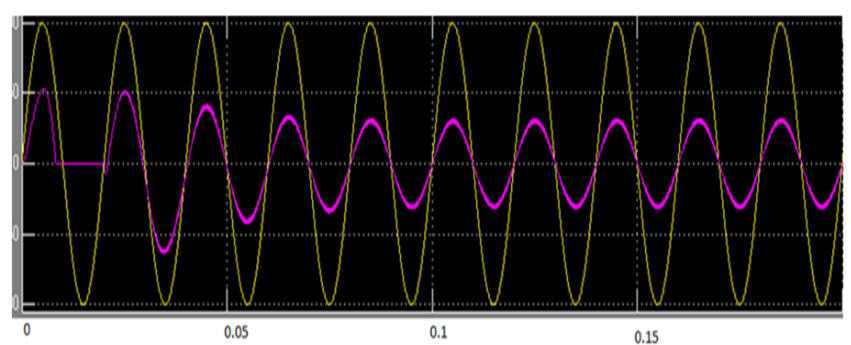

Fig 5.Source voltage (yellow) and improved sinusoidal source current waveforms (purple).

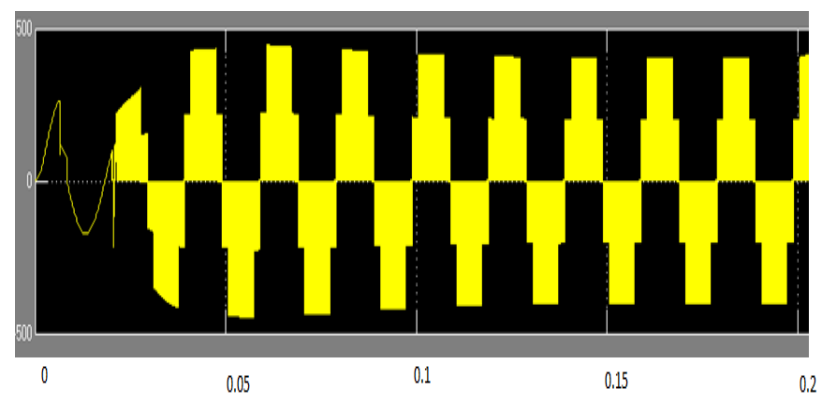

Fig 6. Five level line to line voltage waveform 


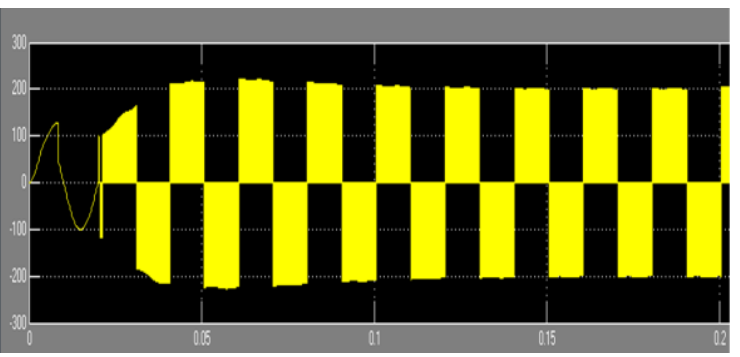

Fig.7. Three level phase to phase voltage waveform

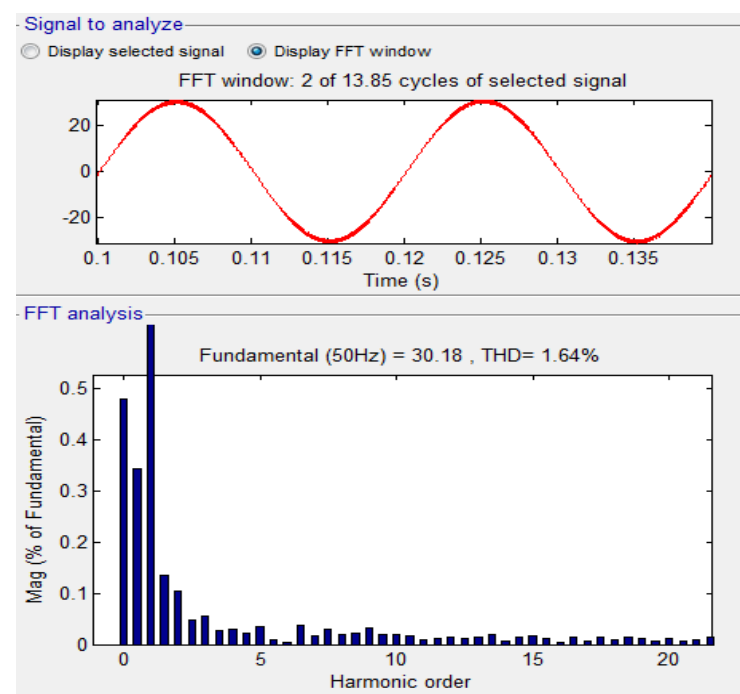

Fig 8: Harmonic spectrum of phase A source current on using NPC converter.

The proposed NPC converter using SPWM technique shows a better performance in terms of THD which is shown in Figs 5-11. Fig. 5 shows the phase $A$ source voltage and line-current waveforms for the NPC converter. It is observed from this figure that the converter draws a sinusoidal current from the source at nearly unity power factor. Fig 6 shows line to line voltage waveform with 5 levels of $\mathrm{V}, \mathrm{V} / 2,0,-\mathrm{V} / 2,-\mathrm{V}$ and Fig 7 shows phase voltage waveform with three levels of $\mathrm{V} / 2,0,-\mathrm{V} / 2$ and here $\mathrm{V}=400$ volts.

Fig. 8 shows FFT analysis with frequency spectrum of line-current drawn by the proposed NPC converter. The line-current THD is $1.64 \%$. It is to be noted that the proposed controller had a reduced THD compared to the fully controlled rectifier.(refer Fig 4 and Fig.8)

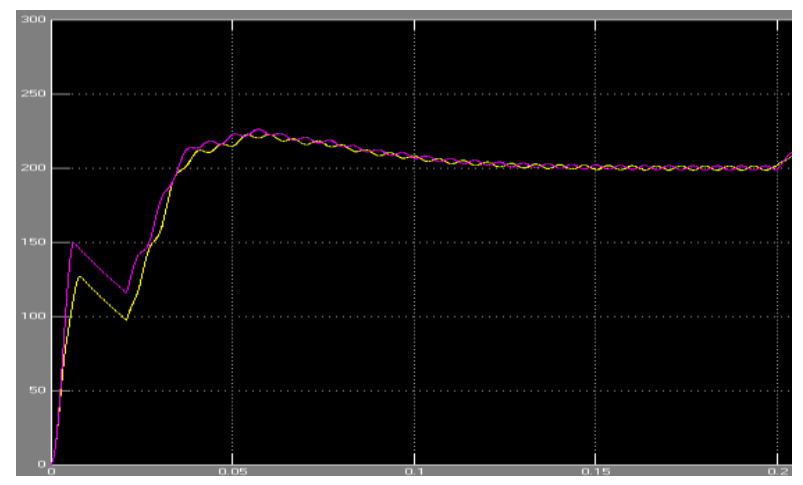

Fig 9. $V_{1}$ (yellow) and $V_{2}$ (purple)voltages across two capacitors $C_{1}$ and $C_{2}$. 


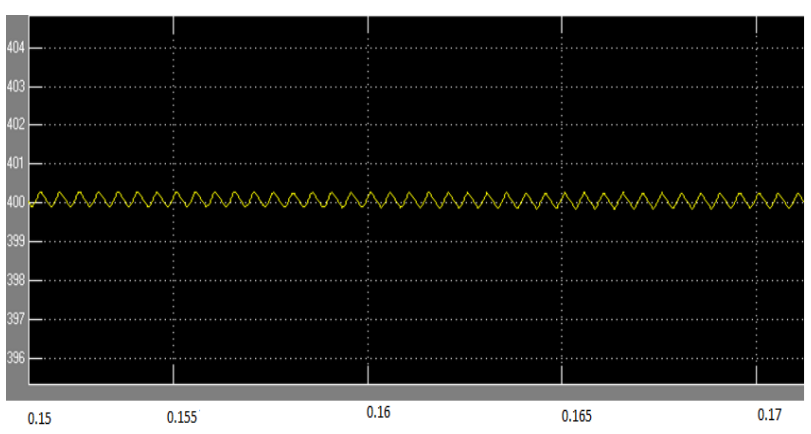

Fig 10: DC bus voltage of rectifier

Fig.9 shows the DC-bus capacitor voltages, V1 and V2. The use of capacitor voltage controller results in a lesser DC-bus capacitor voltage unbalancing problem as shown in Fig.9. Fig. 10 shows the load voltage waveform. It is observed that the load voltage is regulated at the desired reference value of 400 volts with a smaller ripple factor of only 0.7 volt. If we change the load also the source current is sinusoidal and settling quickly it is shown in Fig. 11. When there is no load change the source current and voltage is shown in Fig.5.

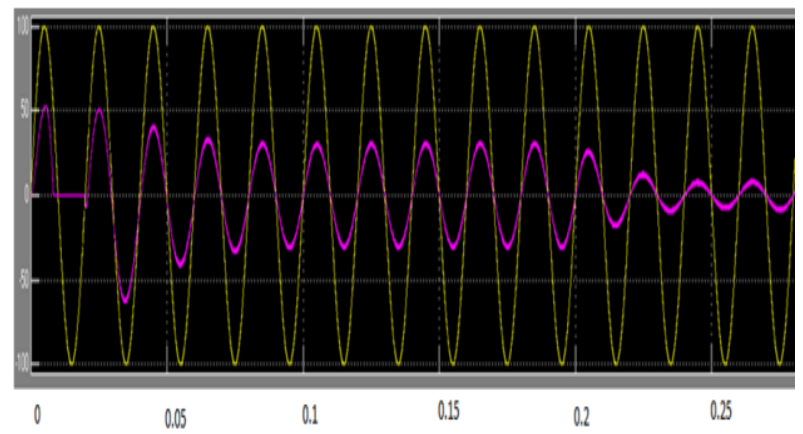

Fig 11: Source voltage (yellow) and source current waveform (purple) on load perturbation.

\section{Conclusion}

The paper presents the performance of three level neutral point clamped converter for improving power quality with the help of Matlab/ Simulink. The results obtained shows reduced THD according to IEEE standards when source current becomes sinusoidal and in phase with voltage. However number of levels can be increased and with increase in number of levels, the synthesized output waveform adds more steps, producing a staircase wave which approaches the sinusoidal wave with minimum harmonic distortion. Ultimately, a zero harmonic distortion wave can be obtained but higher levels also mean higher voltages can be spanned by series devices without device voltage sharing problems. Unfortunately, the number of achievable levels is quite limited not only due to voltage unbalance problem but also due to voltage clamping requirement, circuit layout, and packaging constraints. However it is clear that the development of power electronic devices, the changes and evolution of the industrial processes, and new more demanding standards and regulations will drive and shape the future of multilevel converter technology.

\section{References}

[1]. M. Bollen, Understanding Power Quality Problems: Voltage Sags and Interruptions, New York, Wiley-IEEE Press, 1999

[2]. R. C. Dugan, M. F. Granaghan, S. Santoso, and H. W. Beaty, Electrical Power Systems Quality, 2nd Edition, McGraw Hill, 2004

[3]. IEEE Recommended Practices and Requirements for Harmonics Control in Electric Power Systems, IEEE std. 519, 1992.

[4]. Akagi H., "New Trends in active filters for power conditioning," IEEE Trans. on Industry Applications, vol. 32, Nov./Dec. 1996, pp. 1312-1322

[5]. El-Habrouk M., Darwish M. K., and Mehta P., “Active power filters: a review”, Proc. IEEE Electric Power Applications, vol. 147, pp. 493-513, Sept. 2000.

[6]. Jain S., Agarwal P., and Gupta H. O., "Design, simulation and experimental investigations on a shunt active power filter for harmonics and reactive power

[7]. Singh B., Al. Haddad K., and Chandra A., "A review of active filters for power quality improvement," IEEE Trans. on Industrial Electronics, vol. 46, Oct. 1999, pp. 960-971.

[8]. A.H. Bhat and P. Agarwal, - Three-phase, power quality improvement AC-DC converters, $\|$ Elsevier Electric Power Systems Research, pp. 276-289, 2008. 
[9]. Singh B., Singh B. N., Chandra A., Al-Haddad K., Pandey A., and Kothari D. P., "A Review of Three-Phase Improved Power Quality AC-DC Converters", IEEE Trans. on Industrial Electronics, vol. 51, No. 3, June 2004, pp. 641-660.

[10]. Lai J. S. and Peng F. Z., "Multilevel converters: A New Breed of Power Converters", IEEE Trans. on Industry Application, vol. IA32, No. 3, May/June 1996, pp. 509-517

[11]. Marchesoni M. and Tenca P., "Diode-clamped multilevel converters: A practicable way to balance dc-link voltages," IEEE Trans. on Industrial Electronics, vol. 49, no. 4,August 2002

[12]. Sinha G. and Lipo T. A., "A four-level rectifier-inverter system for drive applications," IEEE Industry Applications Magazine, vol. 4, Jan./Feb. 1998, pp. 66-74

[13]. Tamai S., Koyama M., Fujii T., Mizoguchi S. and Kawabata T., "3 level GTO converter inverter pair system for large capacity induction motor drive," in Conf. Power Electronics and Applications, 1993, pp. 45-50.

[14]. Yacoubi L., Al-Haddad K., Fnaiech F., and Dessaint L. A., "A DSP-Based Implementation of a New Nonlinear Control for a ThreePhase Neutral Point Clamped Boost Rectifier Prototype," IEEE Trans. on Industrial Electronics, vol. 52, No. 1, Feb. 2005, pp. 197205

[15]. A. Nabae, I.Takahashi, and H. Akagi, “A new neutral-point clamped PWM inverter," IEEE Trans Industry Applications,Vol.IA17, No.5, Sep./Oct., 1981, pp.518-523.

[16]. F.Z.Peng,J.S.Lai,J.W.McKeever,and J. VanCoevering, "A multilevel voltage-source converter system with balanced dc voltages," in press, to be presented inconf.Rec.IEEE Power Electronics Specialists Conference (PESC), jun,1995.

[17]. Bendre A., Krstic S., Meer J. V., and Venkataramanan G., "Comparative Evaluation of Modulation Algorithms for Neutral-PointClamped Converters", IEEE Trans. On Industry Applications, vol. 41, no. 2, March/April 2005, pp. 634-643.

[18]. Omedi T. J. and Barlik R., "Three-phase AC-DC unidirectional PWM rectifier topologies- selected properties and critical evaluation", in IEEE ISIE'96, 1996, pp. 784-789.

[19]. S. Kouro, M. Malinowski, K. Gopakumar, J. Pou, L. G. Franquelo, B.Wu,J. Rodriguez, M. A. Perez, and J. I. Leon, "Recent advances and industrial applications of multilevel converters,"IEEE Trans. Ind. Electron., vol. 57, no. 8, pp. 2553-2580, Aug. 2010

[20]. T. B. Soeiro and J. W. Kolar, "The new high efficiency hybrid neutralpoint-clamped converter," IEEE Trans. Ind. Electron., vol. 60, no. 5,pp. 1919-1935, May 2013.

[21]. T. Bruckner, S. Bernet, and H. Guldner, "The active NPC converter and its loss-balancing control," IEEE Trans. Ind. Electron., vol. 52, no. 3, pp. 855-868, Jun. 2005.

[22]. D. Floricau, E. Floricau, and G. Gateau, "Three-level active NPC converter:PWM strategies and loss distribution," in Proc. IEEE IECON, 2008, pp. 3333-3338

[23]. P. Barbosa, P. K. Steimer, M. Winkelnkemper, J. Steinke, and N. Celanovic, "Active-neutral-point clamped (ANPC) multilevel converter technology," in Proc. EPE Conf., 2005, pp. 11-14.

[24]. S. R. Pulikanti, M. S. A. Dahidah, and V. G. Agelidis, "Voltage balancing control of three-level active NPC converter using SHEPWM," IEEETrans. Power Del., vol. 26, no. 1, pp. 258-267, Jan. 2011.

[25]. S. Srikanthan and M. K. Mishra, "DC capacitor voltage equalization in neutral clamped inverters for DSTATCOM application," IEEE Trans. Ind.Electron., vol. 57, no. 8, pp. 2768-2775, Aug. 2010

[26]. J. Pou, J. Zaragoza, S. Ceballos, M. Saeedifard, and D. Boroyevich, "A carrier-based PWM strategy with zero-sequence voltage injection for athree-level neutral-point-clamped converter," IEEE Trans. Power Electron.,vol. 27, no. 2, pp. 642-651, Feb. 2012

[27]. J. Shen, S. Schr" oder, R. R" osner, and S. El-Barbari, "A comprehensive study of neutral-point self-balancing effect in neutral-pointclamped three level inverters," IEEE Trans. Power Electron., vol. 26, no. 11, pp. 3084-3095, Nov. 2011.

[28]. H. D. T. Mouton, "Natural balancing of three-level neutral-point-clamped PWM inverters," IEEE Trans. Ind. Electron., vol. 49, no. 5, pp. 1017-1024,Oct. 2002.

[29]. A.H Bhat and P.Agarwal-"A comparative evaluation of three phase high power factor boost converters for power quality improvement,” IEEE Trans. Ind. tech.,pp-546-551,2000 